\title{
Operational effects of speed breakers: a case study in India
}

\author{
Malaya Mohanty ${ }^{1}$, Yash Raj $^{2}$, Subhangee Rout ${ }^{3}$, Utkarsh Tiwari ${ }^{4}$, \\ Sagarika Roy ${ }^{5}$, Satya Ranjan Samal ${ }^{6}$ \\ ${ }^{1,6}$ Assistant Professor, KIIT University,Bhubaneswar, India, malaya.mohantyfce@kiit.ac.in \\ ${ }^{2}$ B.Tech Student, KIIT University, Bhubaneswar, India, 1701207@kiit.ac.in \\ ${ }^{3}$ B.Tech Student, KIIT University, Bhubaneswar, India,1701190@kiit.ac.in \\ ${ }^{4}$ B.Tech Student, KIIT University, Bhubaneswar, India,1701203@kiit.ac.in \\ ${ }^{5}$ B.Tech Student, KIIT University,Bhubaneswar,India,1701172@kiit.ac.in
}

\begin{abstract}
Traffic condition in India is highly heterogeneous consisting of vehicles of different static and dynamic characteristics. The speeds of all vehicles are non-uniform. Therefore, to regulate the speeds of different category of vehicles while travelling on a sharp turn or while approaching towards an intersection or buildings like schools and hospitals, traffic calming devices are provided on the roads. Speed breakers are one of the most commonly used traffic calming devices in developing countries like India. Geometry of the speed breakers are based on IRC 99 which says that the width of speed breakers should be $3.7 \mathrm{~m}$ and the height should be $0.1 \mathrm{~m}$ for urban roads. The codal provisions also suggest that the vehicles should be able to cross the speed breaker at an advisory speed of $20 \mathrm{kmph}$. However, it is observed that most of the speed breakers have faulty geometrical dimensions owing to various problems to the road users. The width of the speed breakers are usually observed to be narrowed down which increases the chance of road crashes due to sudden braking of vehicles encountering it. Further, it also leads to sudden slowing down of the whole traffic stream leading to traffic congestion. It also reduces fuel efficiency of the vehicles leading to overall increase in vehicle operating and maintenance costs. The present study reviews in detail the provisions provided in the IRC code for construction of speed breakers. Thereafter, a practical on field study is conducted to examine the dimensions of various speed breakers across various cities in India, and compare their dimensions with the provisions provided in the IRC code. Further, the operating speed of the vehicles while crossing the speed breaker is also noted down and compared with the suggested speed as provided in the code. Finally, a detailed comparison between speed reduction at the speed breaker and their dimensions has been analyzed. Speed reduction of different category of vehicles has also been examined in detail.
\end{abstract}

Keywords - Traffic safety, Traffic Calming Devices, Speed Breaker

\section{Introduction}

Road traffic accidents and fatalities due to them have been increasing rapidly making it the tenth leading cause of deaths worldwide. (Afrin et al., 2015). World Health Oraganisation's (WHO, 2013) global report on road safety indicates that the total number of road traffic deaths remain alarmingly high at 1.24 million per year around the world. In a developing country like India, which has the second highest population in the world, in 2017 alone, 1.5 lakhs people have lost their lives due to road accidents (MORTH, 
2017). According to MORTH 2017, over speeding accounts for more than 70 percent of road accidents and around 67 percent of road accident deaths. Due to this reason, traffic calming devices are installed on Indian roads. The main purpose of traffic calming systems is to reduce the speed of traffic flow (Pau, 2002). Usually, three techniques are used for achieving desired speed reduction among road users which includes: 1 . Police Enforcement, 2. Visual Stimuli (Warning Signs), and 3. Tactile Stimuli (Attention grabbing devices that produce noise or vibrations in vehicles) (Dixon and Jacko, 1998). The third category involves vertical raising of road pavements known as "humps" or "bumps" (Pau, 2002) which is one of the most commonly used traffic calming devices in India.

Speed-breakers are designed to be driven over at a certain comfortable speed (Jain et al., 2012). In India, IRC 99-2018 is used for designing of traffic calming devices like speed humps. According to the provisions mentioned in the IRC code, the minimum chord length and the height for speed bumps (as shown in Figure 1 below) should be $3 \mathrm{~m}$ and $0.1 \mathrm{~m}$ respectively. The code also mentions that the minimum speed at which a vehicle should cross the hump is $25 \mathrm{kmph}$. However, the preliminary observations on field showed that hardly any speed humps have $3 \mathrm{~m}$ of chord length. Therefore, when a vehicle moves towards a speed-breaker at a higher speed, the risk of road crash becomes significantly high (Jain et al., 2012). Due to faulty design of speed humps, the road user approaching towards the speed hump has to decrease the speed instantly to near $0 \mathrm{kmph}$ (rolling condition) in contrary to prescribed speed of $25 \mathrm{kmph}$ (IRC 99-2018) by applying a full brake. Usually, the following vehicle is not aware of this sudden deceleration of the leading vehicle which may results in a rear-end collision. The condition deteriorates even more with higher degree of faultiness in the geometric design of the speed humps.

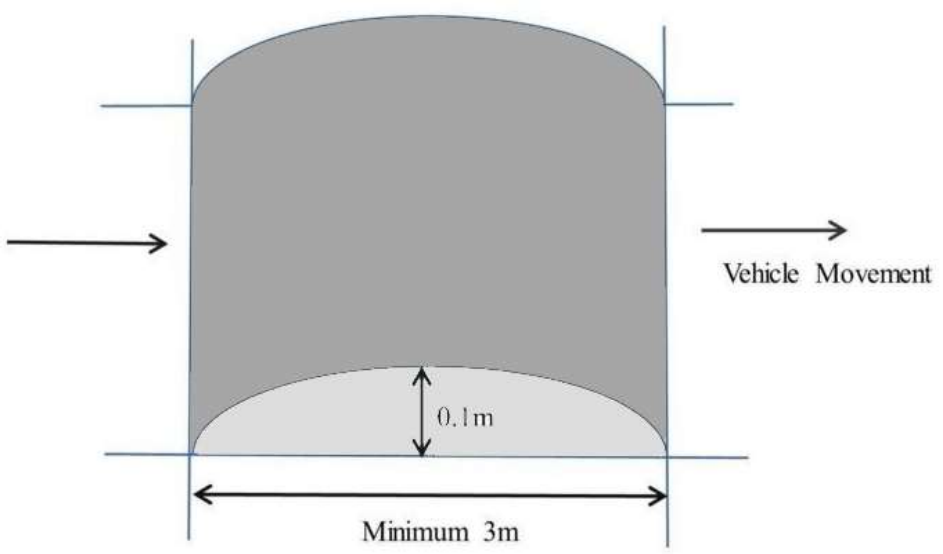

Figure 1 Cross-sectional view of a speed hump with dimensions according to IRC 99:2018.

Many past literature (Pau, 2002; Jain et al., 2012; Antic et al., 2013) have reported excessive decline in speed by vehicles while crossing over the speed bumps. The reports also claim speed bumps to be acting as a traffic flow inhibitor resulting in excess decrease of speed leading to undesirable traffic flow scenario. However, except Antic et al. (2013) not much studies have been found that tries to explore the causes behind this sudden 
decrease of traffic flow at speed bumps. According to Antic et al. (2013), speed bumps of 5 and $7 \mathrm{~cm}$ height should be provided at locations where vulnerable road users are highly endangered and speed bumps of $3 \mathrm{~cm}$ height should be provided at less endangered locations. Further, the safety aspect has also not been considered much by previous studies which is a major area of research for the present times. Moreover, in developing countries like India where heterogeneous traffic condition is predominant, there is not much research conducted on the effect of speed bumps on the road user in terms of speed reduction and safety.

Therefore, the present study aims to survey the speed bumps provided on the arterial roads of a smart city in India and check whether the speed bumps are installed as per the IRC specifications. Secondly, the speed reduction of different category of vehicles to cross the speed bumps is also noted down. Finally, the study also examines the safety of road users moving on these speed bumps by studying deceleration behaviour of the approaching vehicles.

\section{Data Collection and Extraction}

Field data is collected over a stretch of $60 \mathrm{kms}$ on arterial roads of a smart city located in India emanating from NH 16. The most important roads with highest traffic counts in the city of Bhubaneswar, a smart city located in India is selected for the present study. Every speed bumps in both sides of traffic movement has been measured using measuring tape and leveling staff. Chord length, height and arc length of each of the speed bumps were noted down. Further, the position of the speed bump on the map is tagged based on their latitude, longitude, and distance from a common reference point using hand-held GPS device. Speed data was extracted from traffic data recorded on field. 2 cameras were used for recording field data. The camera set up for data collection is shown in Figure 2 below.

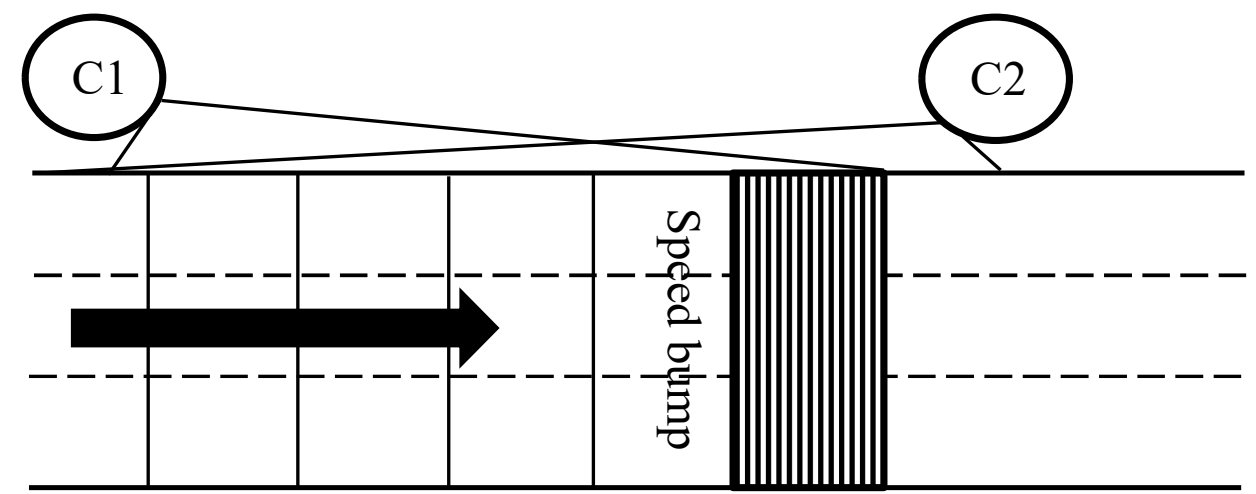

Figure 2 Camera set up for data collection

4 segments of 5 meters each were marked on the upstream of the speed bumps and data were recorded at different periods of day. The time taken for each vehicle to cross these segments of 5 meters were noted down and consequently the speeds of the respective vehicles were obtained.

\section{Results \& Discussions}

Road length of $60 \mathrm{kms}$ emanating from NH 16 has been examined extensively for the presence of speed bumps. The survey was conducted to locate each and every speed bump present on the selected road network. Further, the height of the speed bump, its arc length 
and chord length is measured individually for every speed bump. In addition, the traffic facilities like median openings and intersections were also noted down where the required traffic calming devices has not been provided. Figure 3 depicts the meanings of chord length, height of speed hump, and arc length in context with the present study. According to IRC specifications, usually the humps are either trapezoidal or circular. However, in the considered study area, all the speed humps were designed as circular speed humps.

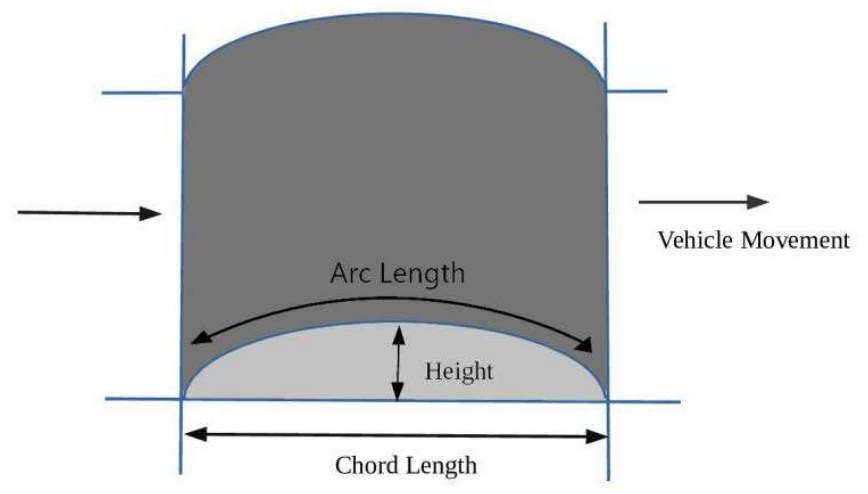

Figure 3 Technical specifications of a speed hump

A total of 12 speed humps were found on the studied road network. The chord length, and height of the speed humps are presented in Table 1 below.

Table 1 Geometrical measurement of speed humps

\begin{tabular}{ccc}
\hline Sl. No. & Chord length $(\mathbf{m})$ & Height $(\mathbf{m})$ \\
\hline 1 & 1.70 & 0.07 \\
\hline 2 & 1.97 & 0.08 \\
\hline 3 & 2.20 & 0.08 \\
\hline 4 & 1.27 & 0.08 \\
\hline 5 & 0.98 & 0.07 \\
\hline 6 & 2.04 & 0.07 \\
\hline 7 & 2.23 & 0.10 \\
\hline 8 & 2.25 & 0.08 \\
\hline 9 & 2.25 & 0.07 \\
\hline 10 & 1.88 & 0.08 \\
\hline 11 & 2.15 & 0.06 \\
\hline 12 & 1.60 & 0.07 \\
\hline Average & $\mathbf{1 . 8 8}$ & $\mathbf{0 . 0 8}$
\end{tabular}

It can be observed from Table 1 that the chord length of speed humps varies from 0.98 $\mathrm{m}$ to a maximum of $2.25 \mathrm{~m}$. The average chord length of speed humps were found to be $1.88 \mathrm{~m}$. Similarly, the height of speed humps varies from $0.06 \mathrm{~m}$ to $0.10 \mathrm{~m}$, with an average height found to be $0.08 \mathrm{~m}$. Table 2 below shows the IRC guidelines for the design of circular speed humps. It should also be noted that according to IRC provisions, the maximum rise/height that can be provided for circular humps is $0.1 \mathrm{~m} / 10 \mathrm{~cm}$. 
Table 2 Recommended chord length, circular humps (Maximum rise:10 cm)

\begin{tabular}{ccc}
\hline Desired speed & Chord length & Bus speed during passage \\
\hline $20 \mathrm{~km} / \mathrm{h}$ & $3.0 \mathrm{~m}$ & $5 \mathrm{~km} / \mathrm{h}$ \\
\hline $25 \mathrm{~km} / \mathrm{h}$ & $3.5 \mathrm{~m}$ & $10 \mathrm{~km} / \mathrm{h}$ \\
\hline $30 \mathrm{~km} / \mathrm{h}$ & $4.0 \mathrm{~m}$ & $15 \mathrm{~km} / \mathrm{h}$ \\
\hline $35 \mathrm{~km} / \mathrm{h}$ & $5.0 \mathrm{~m}$ & $20 \mathrm{~km} / \mathrm{h}$ \\
\hline $40 \mathrm{~km} / \mathrm{h}$ & $6.5 \mathrm{~m}$ & $25 \mathrm{~km} / \mathrm{h}$ \\
\hline $45 \mathrm{~km} / \mathrm{h}$ & $8.0 \mathrm{~m}$ & $30 \mathrm{~km} / \mathrm{h}$ \\
\hline $50 \mathrm{~km} / \mathrm{h}$ & $9.5 \mathrm{~m}$ & $35 \mathrm{~km} / \mathrm{h}$ \\
\hline
\end{tabular}

It can be clearly seen from Table 2 that the minimum chord length for installation of speed humps is $3 \mathrm{~m}$ according to IRC specifications. However, data from Table 1 suggests that the speed humps constructed on the arterial roads are faulty. On an average, the chord lengths of all the speed humps are 40 percent less than the minimum prescribed chord length according to IRC 99-2018. However, the rises provided for the speed humps follow the codal provision of maximum $0.1 \mathrm{~m}$. This shorter chord length of speed humps lead the vehicles to suddenly brake their vehicles before a speed hump, and negotiate a rough ride while moving over the speed humps. The specifications in IRC suggests that the minimum speed at which a vehicle should approach a speed hump is $20 \mathrm{kmph}$, and for a smooth movement on the speed hump the chord length of the speed hump should be a minimum $3 \mathrm{~m}$ which is not followed in the existing traffic conditions. This lead the vehicles to decelerate at a higher rate to decrease their vehicle's speed to almost rolling condition which causes more wear and tear in the vehicle along with a higher probability of rear-end collision while approaching the speed hump. A detailed survey has been conducted to measure the speed reduction of the vehicles while approaching towards and crossing over the speed humps. It is usually observed from the brake lights of vehicles that the vehicles start to reduce their speed from around 15-20 meters on the upstream of the speed humps. Therefore, the speed of each and every vehicle has been recorded for every $5 \mathrm{~m}$ distance starting from $20 \mathrm{~m}$ on the upstream of the speed hump. Table 3 presents the average speed of all the vehicles as they approach towards the speed humps.

Table 3 Average speed of vehicles while approaching speed bumps

\begin{tabular}{cccccc}
\hline $\begin{array}{c}\text { Distance on the } \\
\text { upstream of speed } \\
\text { humps in m }\end{array}$ & $20-15$ & $15-10$ & $10-5$ & $5-0$ & $\begin{array}{c}\text { On speed } \\
\text { humps }\end{array}$ \\
\hline $\begin{array}{c}\text { Average speed in } \\
\text { kmph }\end{array}$ & 33 & 26 & 23.5 & 18 & 10 \\
\hline
\end{tabular}

It can be observed from Table 3 that the average speed of the vehicles approaching towards a speed hump is only about $10 \mathrm{kmph}$ on the speed hump. Furthermore, it may be noted that none of the vehicles are heavy vehicles (HV) whose speeds have been considered here. Figure 4 shows the trend of vehicle speeds as they move towards a speed hump. It can be observed that there is a sudden drop in speed at around $20 \mathrm{~m}$ on the upstream of speed hump. The speeds of vehicles decrease from $35 \mathrm{kmph}$ at $20 \mathrm{~m}$ on the upstream of speed hump to $9.6 \mathrm{kmph}$ on the speed hump. This sudden decline in speed results in higher chances of rear end collisions mainly at higher traffic volumes. The speed 
statistics has been used to calculate the deceleration behaviour of the vehicles at every 10 meters, starting from $70 \mathrm{~m}$ to $20 \mathrm{~m}$ on the upstream of speed hump and at an interval of every $5 \mathrm{~m}$ from $20 \mathrm{~m}$ upstream of speed hump upto the instant when vehicles cross the speed humps. Since the vehicle speeds at every interval along with the distances of the intervals are known, therefore by usage of equations of motion, deceleration rate for every interval is easily calculated. The deceleration rates at every interval is presented in Table 4.
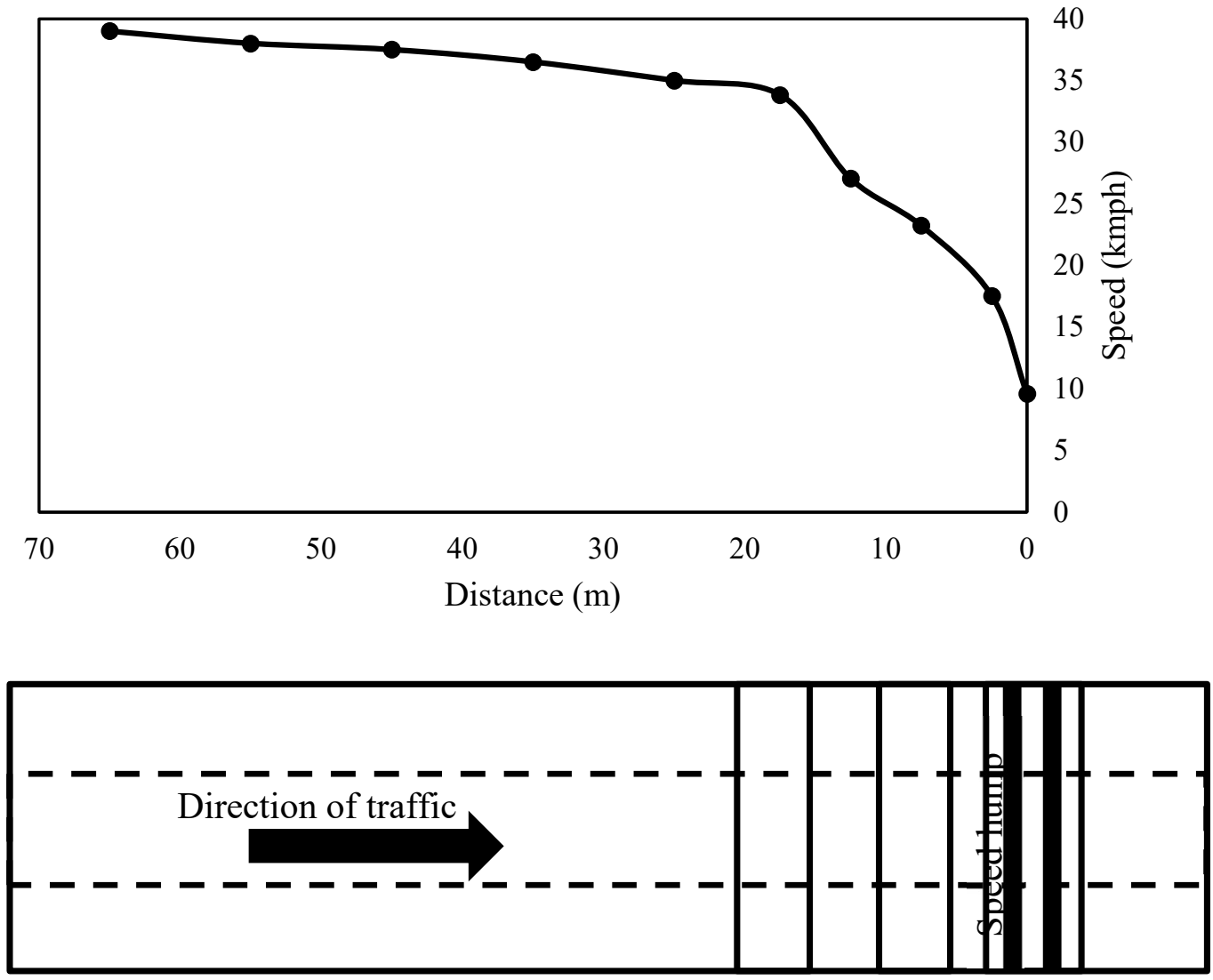

Figure 4 Variation of speed as vehicles approach speed humps

Table 4 Average deceleration of vehicles while approaching speed bumps

\begin{tabular}{ccccc}
\hline $\begin{array}{c}\text { Distance on the upstream of speed } \\
\text { humps in } \mathbf{m}\end{array}$ & $\begin{array}{c}17.5- \\
12.5\end{array}$ & $\begin{array}{c}12.5- \\
7.5\end{array}$ & $\begin{array}{c}7.5- \\
2.5\end{array}$ & $\begin{array}{c}2.5 \text {-speed } \\
\text { hump }\end{array}$ \\
\hline Average deceleration in $\mathbf{~ m} / \mathbf{s}^{\mathbf{2}}$ & 3.18 & 1.48 & 1.79 & 3.79 \\
\hline
\end{tabular}

Table 4 shows that at around $15 \mathrm{~m}$ on the upstream of speed hump and just while crossing the speed hump, the effect of braking in the vehicles is highest and hence highest deceleration rate is observed during these two phases. However, the average deceleration rate at other intervals are also relatively high considering the values of maximum deceleration recorded by previous researchers. Many researchers (Bennett and Dunn, 1995; Akçelik and Besley, 2001; Wang et al., 2005; Wortman and Fox, 1994) have 
reported maximum deceleration rates in the range of $2.5 \mathrm{~m} / \mathrm{s}^{2}$ to as high as $4 \mathrm{~m} / \mathrm{s}^{2}$. In developing country like India, the traffic conditions comprise of heterogeneous traffic with no lane discipline. Therefore, directly assuming a deceleration value which is unsafe for the road is impractical. In India, IRC-66:1976 is used to provide the minimum sight distance on highways. Sight distance is the clear distance ahead needed by a driver to stop his vehicle before meeting a stationary object in his path on the road (IRC 66:1976). The minimum stopping sight distance for any vehicle is calculated by using the following equation.

$$
\mathrm{SSD}=0.278 * \mathrm{v} * \mathrm{t}+\left(\mathrm{v}^{2} / 254 * \mathrm{f}\right)
$$

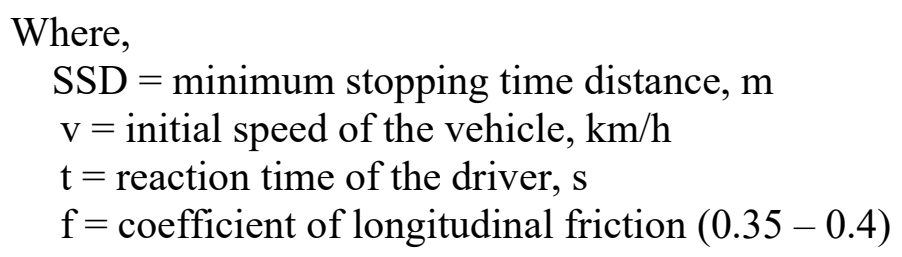

In this equation, the first part $(0.278 * \mathrm{v} * \mathrm{t})$ is called the lag distance/ the distance travelled before being able to perceive and react to the traffic condition whereas the second part $\left(\mathrm{v}^{2} / 254 * \mathrm{f}\right)$ is denoted as the braking distance/the actual distance covered while slowing the vehicle from $\mathrm{v}$ to 0 . A reaction time of $2.5 \mathrm{~s}$ has been considered by IRC to calculate the lag distance. However, in the present study it is observed that while approaching a speed breaker, the drivers have already perceived the situation beforehand. This is evident from a speed study conducted at a midblock section which revealed higher speeds of around $45 \mathrm{kmph}$ at midblock sections as compared to the approaching speed of around $35 \mathrm{kmph}$ at $20 \mathrm{~m}$ upstream of speed breakers. Therefore, the drivers don't need the reaction time to perceive the speed breakers; rather they can just apply brakes when they wish, to slow down their vehicle. A calculation has been conducted to find the minimum braking distance as per IRC-66:1976 when a vehicle is running at $33 \mathrm{kmph}$ (Table 3). Applying the braking distance formula (Equation 1) and considering the value of ' $\mathrm{f}$ ' as 0.4 , the braking distance comes to be $11 \mathrm{~m}$. Thus, if a vehicle is moving with a speed of $33 \mathrm{kmph}$, and it applies brakes fully, it will travel $11 \mathrm{~m}$ before coming to a stop. Taking into account this minimum distance to stop $(11 \mathrm{~m})$, initial speed $(33 \mathrm{kmph})$, and final speed $(0 \mathrm{kmph})$, rate of deceleration is calculated using the following equation of motion.

$$
\mathrm{v}^{2}-\mathrm{u}^{2}=2 * \mathrm{a} * \mathrm{~s}
$$

Where, $v$ is final speed in $\mathrm{m} / \mathrm{s}$;

$\mathrm{u}$ is initial speed in $\mathrm{m} / \mathrm{s}$;

$\mathrm{s}$ is the minimum stopping distance in $\mathrm{m}$;

$\mathrm{a}$ is the acceleration/deceleration rate in $\mathrm{m} / \mathrm{s}^{2}$

The obtained deceleration rate is $3.81 \mathrm{~m} / \mathrm{s}^{2}$. Since, $11 \mathrm{~m}$ is the minimum distance for a vehicle at a speed of $33 \mathrm{kmph}$ to stop, therefore $3.81 \mathrm{~m} / \mathrm{s}^{2}$ is the maximum safe deceleration rate of a vehicle. Any vehicle decelerating at higher rate than $3.81 \mathrm{~m} / \mathrm{s}^{2}$ is dangerous which may lead to skidding or slipping of vehicle or increase the probability of rear end collision with the following vehicle. In the present study, the percentage of 
unsafe vehicles at different segments of road (every $5 \mathrm{~m}$ interval on the upstream of speed breakers) has been estimated based on their deceleration rates. Table 5 shows the proportion of safe and unsafe vehicles at various segments on the upstream of speed breakers.

Table 5 Proportion of safe \& unsafe vehicles while approaching a speed breaker

\begin{tabular}{ccc}
\hline $\begin{array}{c}\text { Distance on the } \\
\text { upstream of speed } \\
\text { breaker, } \mathbf{~}\end{array}$ & $\begin{array}{c}\text { \% of safe vehicles } \\
\text { (Deceleration } \mathbf{3 . 8 1} \mathbf{~ m} / \mathbf{s}^{\mathbf{2}} \text { ) }\end{array}$ & $\begin{array}{c}\text { \% of unsafe vehicles } \\
\text { (Deceleration } \mathbf{3 . 8 1} \mathbf{~ m} / \mathbf{s}^{\mathbf{2}} \text { ) }\end{array}$ \\
\hline $12.5-17.5$ & 69.4 & 30.6 \\
\hline $7.5-12.5$ & 93.9 & 6.1 \\
\hline $2.5-7.5$ & 95.9 & 4.1 \\
\hline On speed breaker -2.5 & 91.8 & 8.2 \\
\hline
\end{tabular}

Results reveal that at around $15 \mathrm{~m}$ on the upstream of speed breaker, the vehicles try to recklessly apply brakes to reduce their speed to the maximum extent. One of the main reasons for such driving behavior might be because of the fact that the average width (chord length) of speed breakers are $40 \%$ less than the prescribed dimensions in IRC99:2018. This lessened chord length of speed breakers cause an abrupt change in height on the road leading the drivers to suddenly brake their vehicles before $15 \mathrm{~m}$ of the oncoming speed breaker to reduce their speed to around $10 \mathrm{kmph}$ which is much less than the prescribed minimum speed of $20 \mathrm{kmph}$.

\section{Recommendations}

The results of the present study clearly reveals that the presence of faulty speed breakers on urban roads causes drivers to face discomfort. This leads them to suddenly brake their vehicles beyond maximum safe deceleration rate which may lead to skidding or slipping of vehicles or even rear end collision if the following vehicle is unaware of it.

The first and foremost recommendation is to build all the speed breakers according to the prescribed code of practice. However, for the already existing speed breakers which are faulty, there are two recommendations. Firstly, if budget of the country permits, then all the speed breakers should be reconstructed. However, if the first recommendation cannot be applied, then there should be two warning signs on the upstream of speed breaker; one mentioning that 'faulty speed breaker ahead; drive slowly' and second mentioning the speed limit of $10 \mathrm{kmph}$. These signs should be placed at 50 to $60 \mathrm{~m}$ on the upstream of median opening as according to IRC-66:1976, a vehicle moving at 45-50 $\mathrm{kmph}$ requires 45 to $60 \mathrm{~m}$ to completely stop their vehicle.

\section{Conclusions}

The present study deals with the geometric analysis of speed breakers in a smart city in India and subsequent effect of the faulty design on road users. It is observed that in India, heterogeneous traffic condition is followed where non-lane based movement is followed by the vehicles. In order to design the traffic rules, various IRC codes are used. IRC 99:2018 provides the specification for installation of traffic calming devices like speed breakers. According to IRC 99:2018 the minimum speed at which the vehicle should approach towards the speed hump is at least $20 \mathrm{kmph}$. Likewise, the minimum 
chord length and height of the speed hump should be $3 \mathrm{~m}$ and $0.1 \mathrm{~m}$ respectively for smooth movement of vehicles. The present study is conducted at smart city 'Bhubaneswar', where most of the speed breakers were found to be circular. Preliminary observations on field showed that hardly any speed humps have $3 \mathrm{~m}$ of chord length. A detailed investigation revealed that the average chord length and average height of speed humps were measured to be $1.88 \mathrm{~m}$ and $0.08 \mathrm{~m}$ respectively. On an average, the chord lengths of all the speed humps are 40 percent less than the minimum prescribed chord length according to IRC 99-2018. The shorter chord length of speed humps might cause the vehicles to suddenly apply brake before a speed hump, and negotiate a rough ride while moving over the speed humps. In order to study this phenomenon, a speed study has been conducted for the vehicles approaching towards speed humps. The study was conducted from a distance of $20 \mathrm{~m}$ upstream of speed hump at a regular interval of $5 \mathrm{~m}$. it was observed that the average speed of the vehicles reduced from $33 \mathrm{kmph}$ at $20 \mathrm{~m}$ to $9.8 \mathrm{kmph}$ on the speed hump. This sudden decline in speed may result in high chances of rear end collisions mainly at heavy traffic volumes. This finding is further confirmed by the deceleration values obtained from the field. Deceleration values ranging from $0 \mathrm{~m} / \mathrm{s}^{2}$ to $11 \mathrm{~m} / \mathrm{s}^{2}$ were determined from the field data.

IRC 66:1976 is used for specifying the minimum stopping sight distance on roadways. According to the provisions of the code, a vehicle travelling at $33 \mathrm{kmph}$ requires $11 \mathrm{~m}$ to come to a halt. Therefore, the maximum safe deceleration rate was found to be $3.81 \mathrm{~m} / \mathrm{s}^{2}$. Hence, if any vehicle approaching towards a speed hump, decelerates at a rate higher than $3.81 \mathrm{~m} / \mathrm{s}^{2}$, it will be consider to be dangerous or unsafe. A proportion of safe and unsafe vehicle approaching the speed breaker was calculated and it was observed that approximately $31 \%$ of vehicular movement are unsafe at $12.5-17.5 \mathrm{~m}$ on the upstream of hump. Similarly, $6 \%$ of vehicles are always found to be unsafe while passing over the speed breaker. This can be attributed to the faulty dimension of speed breaker which cause the vehicles to suddenly decelerate, and may result in collision. Further, there will be an increased wear and tear of the vehicles deceasing its efficiency over a time period. Finally, the study recommends either the use of warning signs at a distance of 50-60 m of the upstream of the speed breakers (as per IRC 66:1976), or to reconstruct the speed breakers according to IRC 99:2018 for smooth operation of traffic at speed humps.

\section{References}

Afrin, M., Mahmud, M. R., and Razzaque, M. A. (2015, December). "Real time detection of speed breakers and warning system for on-road drivers", In 2015 IEEE International WIE Conference on Electrical and Computer Engineering (WIECONECE) (pp. 495-498). IEEE.

Akçelik, R., and Besley, M. (2001). "Acceleration and deceleration models", In Proceedings of 23rd Conference of Australian Institute of Transport Research. Monash University Melbourne, Australia.

Antić, B., Pešić, D., Vujanić, M., and Lipovac, K. (2013). “The influence of speed bumps heights to the decrease of the vehicle speed-Belgrade experience", Safety Science, 57, 303-312.

Bennett, C., and Dunn, R.C.M. (1995). "Driver deceleration behaviour on a freeway in New Zealand", Transportation Research Record, 1510, 70-75.

Jain, M., Singh, A. P., Bali, S., and Kaul, S. (2012). "Speed-Breaker Early Warning System", In NSDR. 
Pau, M. (2002). "Speed bumps may induce improper drivers' behavior: case study in Italy", Journal of transportation engineering, 128(5), 472-478.

Wang, J., Dixon, K., Li, H., and Ogle, J. (2005). "Normal deceleration behaviour of passenger vehicles starting from rest at all way stop controlled intersections", Transportation Research Record. DOI: http://dx.doi.org/10.3141/1883-18, 1883: 158166.

Wortman, R.H., and Fox, T.C. (1994). "An Evaluation of Vehicle Deceleration Profiles”, Journal of Advanced Transportation, DOI: http://dx.doi.org/10.1002/atr.5670280303, 28(3): 203-215.

Dixon, M. A., and Jacko, J. A. (1998). "An investigation of tactile and visual stimuli in the roadway environment", Perceptual and motor skills, 87(2), 387-394.

Acknowledgements

I would like to acknowledge KIIT University for its full support for this study. I would also like to appreciate the efforts of my B.Tech project students (in authors list) who worked hard on field without whom this paper would have never been possible. 